Bangl. J. Vet. Med. (2016). 14 (2): 263-269

ISSN: 1729-7893 (Print), 2308-0922 (Online)

\title{
AQUACULTURE HEALTH MANAGEMENT AND BIOSECURITY PRACTISES IN SOUTH WEST OF BANGLADESH
}

\author{
B. Bhowmick ${ }^{*}$ and M. Crumlish \\ Institute of Aquaculture, University of Stirling, Stirling FK9 4LA, United Kingdom
}

\begin{abstract}
Bangladesh is now the world fourth largest inland fish producer and more than half of it comes from aquaculture according to 2012 ranking. The shrimp and prawn industry has gained an important place in the national economy and is the third highest foreign income earner. Concomitant with the growth of the shrimp and prawn culture industry has been the recognition of the ever increasing importance of disease, especially those caused by infectious agents. Few studies have aimed to identify the perception of risk and risk management strategies for small scale aquaculture facilities. The aim of this study was to understand existing health management practices in regards to water management practices and salinity in southwest coastal region of Bangladesh. Questionnaires were specifically designed to gather information on shrimp and prawn culture systems and multiple variables relating to disease outbreaks. A total of eight variables related to health management practices throughout production cycle were investigated comprising location of farm from primary source of water, pond preparation technique, water management practices, in-pond nursing of post larvae (PL), source of PL, salinity level, stocking density and bio security practices. The results found that sharing of water source with other farms, non tested PL, high salinity level, shallow pond, lack of in-pond nursing were considered as diseases risk factors for poly-culture farming system. Furthermore, rainy season (June-August) is risk factors for diseases outbreak because sudden change of salinity level and drop temperature due to rain and freshwater upstream flow. However, risk factors are not direct causes of mortality; instead, risk factors contribute to mortality.
\end{abstract}

Key words: Poly-culture Farming System. Peneaeus monodon (Shrimp), Macrobrachium rosenbergii (Prawn), Salinity, Risk factors, Mortality, Post Larvae (PL), Source of Water and Existing Health Management System

\section{INTRODUCTION}

Although shrimp and prawn farming is become highly profitable, it also becomes seen as high risk, with viral especially White Spot Syndrome Virus (WSSV) and bacterial diseases. Current estimates predict that up to 60\% of total shrimp production is lost annually ( $>$ \$bn) and this loss is mainly accredited to disease (Stentiford et al., 2011). However, not sufficient research has been done in order to mitigate the risk factors in respect to health management practices. This paper was carried out to understand current health management, bio-security practices and associated risk factors of diseases outcome. This study has three research questions, firstly, Nontested PLs associated with common source of water distribution from Primary River and lack of drainage infrastructure in individual farm is likely to be a major risk disease factor and constraint for production intensification in southwest of Bangladesh. Secondly, Mortality rate is low in transitional zone in between the fresh and brackish water (ICZ-'Inter saline-freshwater convergence zone') because salinity level is low. Finally, Short time in-pond nursing PL associated with modified improved culture system can significantly improve survival rate during first 2-3 weeks of post larvae and provide recommendations for improved farm health management appropriate to farmer management capacities and resource availability in low-input output system.

\section{MATERIALS AND METHODS}

A mixed method was adopted which include semi-structured interviews and key informant interview to help understand the actual health management practices being applied in the study areas.

*Corresponding e-mail address: bbhowmick00@gmail.com

Copyright ( 2016 Bangladesh Society for Veterinary Medicine

All rights reserved 0385/2016 


\section{B. Bhowmick and M. Crumlish}

\section{Study area}

Two research projects: Sustainable Ethical Aquaculture Trade project (SEAT, Murray 2013) and Golda (Macrobrachium rosenbergii) (Prawn) ex-post analysis identified (Taskov, 2014) identified 19 and 5 villages respectively running across Khulna, Bagerhat and Sathkhira districts in South West of Bangladesh. Using data provided from these 24 villages as a sample frame, 11 villages were identified for exploratory analysis on the basis of systematic random sampling. The survey was done through questionnaire and rapid rural appraisal method including two focus group discussion, farm walks and direct observation from May, 2015 to June, 2015.

\section{Sample design}

Sampling involves selecting a number of individuals for a study in such a way that individuals represent the whole population (Patton, 2002). In this study, probability sample method was used in such a way that each number of populations had same probability of being selected. More specifically, samples were selected randomly that means every members of population have the same probability of being selected. This was performed selecting every second number of villages from the SEAT and Golda project (C04, C06, C08, C10, C12, C14, C16, C18, C20, C22 and C24). Picking villages randomly from target population (SEAT and Golda project) does not exclude any important factors which were related with study population. Secondly, a stratified sample is a sampling technique in which the researcher divided available population into relevant sub-groups called strata (Patton, 2002).Under the stratified random sampling, population were divided into three different groups on the basis of salinity range- High (Magurkhali), Medium (Gutudia), Low (Badukhali) and taken one village from each group/strata for doing in-depth analysis in second phase.

\section{Data collection method}

The study was divided into 2 phases and the data were collected using a semi-structured questionnaire conducted by face-to- face interview, transect walks and 2 key informant interview from each village to specifically discuss 6 key risk factors for disease outbreak. Three villages were selected for Phase Two; with selection based on key criteria linked to health management practices and bio-security.

\section{Phase One (exploratory)}

Two key informants (KI) and three farmers from each of the 11 villages were interviewed using semistructured questions. Each KI was interviewed using identical surveys to facilitate triangulation, providing greater accuracy of information.

\section{Salinity measurements}

The refractometer salinity measurements provided a degree of objective validation of qualitative information provided by the key informants (KI) on salinity trends. As salinity is major factors for causing diseases, these primary results gave opportunity to explore more in-depth research.

\section{Animal losses}

In an initial exploratory phase, shrimp and prawn losses were estimated by farmer's record for one year period from January, 2014 to December, 2014. Mortality rate was measured on shrimp and prawn because those species were more influenced by salinity fluctuation. In addition, source of PL, in-pond nursing technique, sharing water were also considered as independent variables which had been linked with existing health management practices.

\section{Second Phase (In depth analysis)}

The baseline information gathered from Phase One identified one key village which had experienced the highest degree of animal losses in V3MA (Magurkhali) up to 80\% with high salinity level (22 ppt). Secondly, V1BA (Badukali) village was from low saline areas. Gutudia (V1GU) was also considered as control group because most of farmers have access to ground water and stocking PCR tested PL.

\section{Animal Samples}

Farmers reported that shrimp was more susceptible to diseases than prawn and only shrimp sample was available on that time. Only Shrimp samples were taken from the 3 village locations selected in the second phase of the sampling strategy. The farmer provided the samples from the same pond during the visit and the "diseased status" was according to their opinion and correlates their findings with observation such as trends of mortality rate, abnormal swimming behaviour, history of feeding intake and any spot on carapace, appendages. Each 
shrimp was observed grossly for any clinical signs of disease including growth; abnormalities discolouration etc. and then sections were taken as described in (Lightner, DV 1996) and placed directly into labelled pots containing Davidsons fixative for 24 hours (Lightner, DV 1996). Once transferred into $70 \%$ ethanol these were then transported and placed into wax blocks and 5um thick sections cut prior to staining with H\&E (FAO, 1999). Microtome sections (4-5 $\mu \mathrm{m}$ thick) were prepared, stained with hematoxylin and eosin and observed under microscope. These were observed under light microscopy for finding of the cells and tissues originating from the ectoderm and mesoderm. More importantly, these cells have shown hypertrophied nuclei that stain red in the early stages of infection and dark blue in the later stages.

\section{RESULTS AND DISCUSSION}

Salinity condition was determining factor on which species was then subsequently farmed. There were three types of village existing in study area namely as high salinity (HISAL1), medium saline (MASAL2) and low salinity (LOSAL3) based on previous work (SEAT, Murray, 2014) and recent observation from May, 2015 to June, 2015. HISAL area covered Alamtala, Putimari, Betbunia, Magurkhali villages the dominant species farmed was shrimp (Penaeus monodon) because the high salinity level ranged from 18-25 ppt, making this the most suitable environment for this species. In initial exploratory analysis of the study in 11 villages reported that highest animal losses found in Magurkhali (80\%) and lowest in Gutudia (25\%) and Badukhali village (47\%) during one year period from January 2014 to December, 2014 in shrimp species.

The mean salinity levels of three villages were $11.09 \mathrm{ppt}$ and salinity finding with refractometer. Lowest mortality (35\%) found in V2GU villages and salinity ranges from 6-8 PPT followed by V1BA (46\%) and V3MA (63\%). High salinity was in V3MA village ranging from 22-23 PPT. It was clearly shown that there was strong association between increasing salinity levels over $10 \mathrm{ppt}$ and mortality rate.

The results revealed that 11 out of 15 farmers in 3 villages were using sharing water source from another Gher (Pond). The results found that there was less mortality that has opportunity to get water directly from primary source. Lowest mortality $25 \%$ and $30 \%$ found in V1BA village because those famers get water directly from primary source whereas highest mortality $72 \%, 71 \%$ and $76 \%$ found in Magurkhali village because farmers sharing water from other Gher. Although more than one factors were responsible for contributing mortality rate. Surprisingly, there was no association between sharing water and mortality in one farm (37\% mortality). The association observed in this farm might be influenced by other factors such as improve bio-security and health management practices. Another factor potentially influencing mortality was the water depth available. The results from the second phase of the study found that only $62.5 \%, 85 \%, 28.5 \%$, farmers in V1BA, V2GU and V3MA respectively, were using proper water depth for cultivating shrimp, prawn and white fish. The average water depth for tropical fresh water prawn and shrimp should be about 1.2-1.5m and 1.5-1.6 meter respectively depending on temperature of the environment (FAO, 2005).

The three selected villages were practicing all pond preparation measures before stocking new batch such as complete dry-out pond, removing sludge, tilling the pond bottom, resealing the pond bottom yearly and majority of farmers used lime (calcium carbonate) and fertilizer at 70-120 kg/ha/year in semi-intensive culture system. The results from phase two showed that none of farmers were tested water quality before stocking such as water temperature, dissolved oxygen, $\mathrm{P}^{\mathrm{H}}$, salinity except visual examination of water colour. As a result, increase chance of water contamination can occurs from previous cycle.

Nearly all of the farms in phase 2 of the study used hatchery produced stocks but none of them used any proxy indicators of health such as checked for size, colour etc prior to stocking. It was found that $71 \%, 28 \%$ and $37.5 \%$ of the farms in Gutudia, Magurkhali and Badukhali respectively stocked with PCR tested PL. High percentage tested PL available in Gutudia which was not the same in the other 3 villages. In summary, the results also reported that 10 out of 22 farms in 3 villages used PCR tested PL and they had good survival rates compared with the farms in the villages that did not test. In V1BA, 37.5\% farmers were using PCR tested PL and their mortality rate was comparatively low (25-35\%) than non-tested PL (50-60\%) within the same village. Lower mortality was found in V2GU and V3MA ranging from (25-30\%) and (40-50\%) respectively for using tested PL. From the second phase study it was found that $71 \%$ of farmers from V2GU village only had their PL stocks tested for the presence of white spot syndrome virus (WSSV). 


\section{B. Bhowmick and M. Crumlish}

Traditionally Bangladesh subdivide the year into three season particularly summer, rainy and winter season are important because temperature variation. There appeared to be a seasonal pattern to the losses in all 3 villages which was higher in the rainy season, particularly in V1BA and V3MA villages. Animal losses were generally lower in V2GU village compared with the other 2 villages in this study. The study found that there were increased animal losses reported by the farmers during and at the beginning of rainy season in three villages. The reason given was sudden temperature drop and salinity changes in the water from the excessive rainfall.

Histopathological changes of hepatopancreas tissues such as vacuolization of hepatic cells were observed in 4 samples. The epithelial pillar cells of secondary lamella of gill tissues showed basophilic intra-nuclear inclusion bodies. In addition to fusion formations made between secondary lamella of infect tissue and the cells which exhibited the nucleus hypertrophy and watery and thin cytoplasm. A history of the culture facility (gross clinical sign observed), species cultured (Peneaeus monodon), or region (epidemic in Bangladesh) and histopathology findings that indicates a likelihood of WSSV infection in 4 out of 6 samples. Further investigation was needed for confirmation

This study aimed to describe the aquaculture sites in 3 regions of Bangladesh and to investigate possible causes of animal losses. Within such systems there were varied causes of the animal losses, not all of them being infectious and so combined methods were applied describe the systems to enable biological samples to be taken to try to identify the causes or risk factors of any animal losses within these varied and unique farming practices. The results from this study clearly showed sharing water practices from farm to farm, sites being stocked with poor quality PL, lack of practicing short time in-pond nursing, long transition time for PL delivery, lack of health management practices and bio-security being applied as the main contributing factors of animal mortality (Mohan, et al., 2008). In these semi-intensive or traditional systems there was a general lack of bio-security being applied or testing the quality of the PL. This was common in such types of systems and yet often because there was a lot of information regarding viral and bacterial disease outbreaks many farms report their mortalities to be due to diseases irrespective of whether these have been confirmed or not. Of course this may be true but without the accurate recording or documentation and laboratory test back up to confirm the cause these was farmer's perceptions. In this study it was often described by the farmers that disease was the cause of the mortalities and yet none of them sent samples to the laboratory for confirmation of cause of mortality nor did they record their losses accurately. Without such information it would be impossible to predict what the cause is and even less so on how to management the health of the stocks. For some farmers this might not be an issue but for others that perhaps wish to intensify or make any kinds of development changes the application of health management must become common practise. Not all practises need to be a financial burden for the farmer; infect in many extensive systems farmers can use cost-effective tools such as swimming behaviour of their larvae prior to stocking. These observation indicators have been used in many developing countries (Chanratchakool, et al., 1998). Irrelevant of what their production system there are a variety of tools that the farmers may use to help manage the health of their stocks.

Average salinity concentrations at the coast are higher in the dry season than in the monsoon, due to lack of freshwater flows from upstream. The salinity normally builds up from October to the late June, and it remains higher during the dry season, usually from February to June. At the end of July, salinity level drops sharply due to upstream flows and rainfall. It was shown that salinity levels over $20 \mathrm{ppt} \mathrm{had} \mathrm{high} \mathrm{mortality} \mathrm{rate} \mathrm{up} \mathrm{to} 76 \%$. The majority of farmers in this study revealed that excessive fluctuations in abiotic factors were considered to be the cause of shrimp losses as water salinity and temperate, low oxygen have been shown to be associated with more disease outbreak in shrimp.

Disease outbreaks in aquaculture are not a simple relationship between the presence of the pathogen and an outbreak. Often there are some predisposing features that can trigger susceptibility in the population. These may be genetic, environmental or husbandry stressors (FAO, 2003). It is often necessary to need less favourable or stress factors to trigger some disease outbreaks. High pond density in same area makes the shrimp and prawn more susceptible to disease because high nutrient sediment, polluted water from neighbour farm. When physiochemical character of water such as high ammonia level, low oxygen and high accumulation of dissolved nutrients content is altered, shrimp and prawn become more susceptible to stress leading to diseases (PaezOsuna, et al., 2003). Not only excessive use of feed but also human food waste such as rice, rice bran along with high stocking density, which contribute to stress in semi-intensive farming systems in Bangladesh. It is risky to share water sources but especially intake of polluted water from neighbour farms often spread bacterial and viral 
diseases from farm to farm. In 1996, Bangladesh has experience animal losses of up to $45 \%$ of its total shrimp production due to epidemic outbreak of WSSV disease (Mazid et al., 2002). There are different ways to reduce stress by implementing strategies such as water exchange in an effort to flush the pond. But in coastal farming condition in Bangladesh, it is not easy to apply because the pond location is often far away from the main water source so famers completely rely on secondary and tertiary water source. In this study it was observed that only $10 \%$ farmers are close enough to a main water source so that the majority of farmers cannot easily exchange their water. Another technique can be used to improve water quality such as decreasing feeding rates and increase aeration technique. None of above techniques was used in this study location

As with all types of aquatic farming, optimal stocking densities must be well established to reduce additional stress within the production system. Improper stocking densities which can be too high or too low can contribute to slow growth, aggression and lead to poor production levels. Stocking densities are usually reported to be 50$300 \times 10^{3}$ individuals/ha and $20-50 \times 10^{3}$ individuals/ha for intensive and extensive shrimp farming systems respectively (FAO, 2005). In the study performed, it was found that the stocking density varied from $40 \times 10^{3}$ individuals/ha to $60 \times 10^{3}$ individuals/ha which was well within the established or recommended ranges. However, in some of the study sites selected farmers practised all year stocking and did not fallow their sites but rather practised a put-in-put-out system. This made is impossible to know what the actual stocking densities were at any time of the production cycle. Mixing stocks and batches of different populations without any quarantine or screening process would leave the system open to potential infections which may of course contribute to production losses. Therefore, it was impossible to accurately define this as a true cause of the animal losses within these systems because culturing different age group within same pond. In that study area, all of farmers keep stocking throughout the year and they all had high mortality. A recent study in Australia found that stocking at $11-13 \mathrm{prawn} / \mathrm{m}^{2}$ have been able to keep growing fresh water tiger prawn without any outbreak of diseases (Australian Prawn Farming Manual, 2006).

In this study it was shown that many farms are too shallow over most of the pond area (approximately $30 \mathrm{~cm}$ ) and the result is migration of shrimp into deeper areas and channels when conditions are unfavourable. These deeper areas may also be unsuitable for other reasons (crowding, static water, low dissolved oxygen) and the result is increased stress to the shrimp. This may result in the occurrence of disease and lower shrimp yield from the pond. Many farms are unable to provide deep water for the shrimp due to problems with high pond elevation, low tidal exchange and high environmental temperature. The other major effect of shallow water in ponds is that the pond is used in alternation with paddy culture - the old paddy roots and stalks provide nutrients, but they also degrade the water quality. This means that entire pond is not contributing to productivity per unit area. Adequate flushing of the pond is desirable in such systems. It is recommended that deeper water in ponds can stabilize these conditions to some extent and ideal water depths for extensive culture range between 1.0-1.5 meters (Eleonor et al., 2010).

A critical 'make or break' step in the shrimp and prawn farming cycle is the selection of good quality postlarvae (PL) and their subsequent stocking in grow out ponds. It is crucial that the farmers stock with the best quality PL. There are many ways to judge PL quality which include visual inspection with or without laboratory tests to ensure that the animals are healthy prior to shipping and stocking in the ponds. Not all tests are universally available and few if any of the farmers used laboratory tests in this study but instead some of them used what might be described as proxy indicators such as visual inspection of colour and size or swimming behaviour prior to stocking their farms. This can be useful and the cheapest option for some farmers but it is limited and in one village in this study farmers selected to also use a laboratory molecular based assay to detect their stocks for the presence of WSSV. This polymerase chain reaction (PCR) test is widely available in many countries farming shrimp, particularly those practising intensive shrimp farming (Islam, 2008) and has been found useful in reducing mortalities due to viral infection or inadvertently introducing carrier stock into the farm (FAO, 2013). This particular assay detects the presence of absence of the viral genes in the PL selected for testing but of course, this is not always sufficient to stop a viral disease outbreak as other exposure route can introduce the virus into the farms even if the PL stocked as PCR negative. This is why maintaining optimal water quality, good husbandry and high bio-security is also important on the farms to help reduce disease outbreaks resulting in shrimp losses. It is common practise in many farming systems to test the PL prior to stocking against common diseases e.g. WSSV which is often performed using molecular PCR test (Nakano et al., 1994). Avoidance of WSSV infection through PCR tested PL is considered as intervention strategy on the basis 


\section{B. Bhowmick and M. Crumlish}

of association between WSSV outbreaks and stocking of non-tested PL. However, none of epidemiological test reported that effect of WSSV in shrimp seed on the occurrence of WSSV infection while adjusting other variables (Withyachumnarnkul, 1999; Peng et al., 2001). In this study it was shown that one village (Gutudia) visited it was found that nearly all of the farmers in this village tested their PL from World fish by PCR prior to stocking and they had good survival rates compared with the farms in the villages that did not test. However, the testing of the PL was not the only difference and so although this is a contributing factor for the better survival of the stocks it is not the only factor and to confirm the perceived benefit of the PCR testing of the PL another study would need to compare like-for-like systems.

There are three different transportation systems from Cox's Bazar to south west region such as Khulna (S1), Bagerhat (S2) and Sathkhira(S3) districts of Bangladesh. Among the three transportation system, S1 is considered as quick and fast. Another two systems (S2 and S3) are taking long time to reach destination roughly 18- 20 hours. Therefore, it would deteriorate the quality of PL, resulting in high mortality rate. Moreover, farmers have less opportunity to get PL directly from hatcheries and farmers are completely relying on middle man. This makes more time to process PL and high price. The study results found that anywhere between 10-18 hours was required for the transition of the PL obtained from the hatchery to the pond irrespective of hatchery source.

PL mortality at early stage of life often occurs when stress by handling, long transportation and acclimation. Therefore, it is necessary to do stock in-pond nursery before being transferred to grow-out ponds. Nursing of PL seed can be done either separated pond or within pond (Islam, 2008). However, such practises were not common in traditional or semi-intensive farming systems as found in this study. Improper nursing of the PL combined with different stress factors such as long transportation time, lack of proper feed for juvenile shrimp, lack of acclimation and all those factors can contribute towards low survival rate and compromise production levels of shrimp and prawn. An experimental study carried out at Brackishwater Station of Bangladesh Fisheries Research Institute, Khulna under modified improved culture system showed that survival rate was significantly higher (9.95\%) when using in-nursing pond than direct stocking (FAO, 2015).

The results from this study found that WSSV is the main cause of animal losses on the basis of farmer's perception without confirmation of diagnostic tests. The majority of farmers in this study are identified WSSV on the basis of clinical sign and symptoms. Four out of 6 samples findings revealed that a likelihood of WSSV infection. The main histopathological features of WSSV infected shrimp were the finding of the cells and tissues originating from the ectoderm and mesoderm. More importantly, these cells have shown hypertrophied nuclei that stain red in the early stages of infection and dark blue in the later stages. Sometimes the chromatin was pressed against the nuclear membrane. These findings were also supported by another study conducted in Bangladesh, where WSSV was the major contributing factors for animal losses (Mazid et al., 2002).

In Bangladesh, shrimp aquaculture has not progressed as much as in China or Thailand, owing to inadequate planning and inappropriate regulations. Unplanned Shrimp and prawn cultivation has multifarious impact in terms of bio-security and overall health effects on aquaculture and imbalance in sustainability. In spite of the negative impacts, the economic importance of shrimp and prawn cannot be overlooked for a developing country like Bangladesh. The existing management practices identified by this study clearly indicate scope for intervention for improving management practices so called 'Better Management Practice' (BMP) (FAO, 2014). The term 'Better Management Practice' (BMP) involves set of management practices that can be adopted by farmers to improve yields of shrimp and prawn within the setting of socio-economic, environmentally sustainable and comply with international principles

\section{ACKNOWLEDGMENTS}

This work was jointly supported by Institute of aquaculture, University of Stirling, UK and special fund from INSPIRE project, British Council and Noakhali Science and Technology University (NSTU), Bangladesh 
Aquaculture health management and biosecurity practises

\section{REFERENCES}

1. Australian Prawn Farming Manual (2006). Health management for profit [Online] Available at: http://aciar.gov.au/files/node/737/Australian\%20prawnfarming\%20manual\%20final.pdf [Accessed 25 July, 2015].

2. Chanratchakool P, Turnbull JF, Funge-Smith SJ, MacRae IH and Limsuwan C (1998). Health Management in Shrimp Ponds Aquatic Animal Health Research Institute, Bangkok. pp 152.

3. Eleonor A, Tendencia B and Johan V (2010). White spot syndrome virus (WSSV) risk factors associated with shrimp farming practices in polyculture and monoculture farms in the Philippines. Aquaculture Elsevier Journal 311: 87-93.

4. FAO (1999). Internal and external anatomy of a penaeid Shrimp [Online] Available at: ftp://ftp.fao.org/docrep/fao/005/y1679e/y1679e04.pdf [Accessed 6 August, 2015].

5. FAO (2003). Health management and biosecurity maintenance in white shrimp (Penaeus Vannamei) hatcheries in Latin America [Online] Available at: http://www.fao.org/docrep/007/y5040e/y5040e00.HTM [Accessed 19 July, 2015].

6. FAO (2005). Shrimp culture: pond design, operation and management [Online] Available at http://www.fao.org/docrep/field/003/ac210e/AC210E05.htm [Accessed at 22 July, 2005].

7. FAO (2014). The State of World Fisheries and Aquaculture [Online] Available at http://www.fao.org/3/ai3720e.pdf [Accessed at 8 August, 2015].

8. FAO (2015). Cultured Aquatic Species Information Programme [Online] Available at http://www.fao.org/fishery/culturedspecies/Penaeus_monodon/en [Accessed 21 July, 2015].

9. Islam ML and Alam MJ (2008). Impact of in-pond nursery shrimp (Penaeus monodon) post larvae on the survival rate and production under modified improved culture system. Progressive Agriculture 19: 167-175.

10. Lightner DV (1996). Handbook of diagnostic procedures for diseases of penaeid shrimp. Special publication of the World Aquaculture Society, Baton Rouge, LA.

11. Mazid MA and Banu ANH (2002). An overview of the social and economic impact and management of fish and shrimp disease in Bangladesh, with an emphasis on small-scale aquaculture. In: Arthur, J.R., Phillips, M.J., Subasinghe, R.P., Reantaso, M.B., MacRae, L.H. (Eds.), Primary Aquatic Animal Health Care in Rural, Smallscale, Aquaculture Development. FAO Fisheries Technical Paper No. 406. FAO (United Nations of the Food and Agriculture Organizations), Rome, Italy, pp. 21-25.

12. Mohan CV, Phillips MJ, Bhat BV, Umesh NR, Padiyar PA (2008). Farm-level plans and husbandry measures for aquatic animal disease emergencies. Revue Scientifique et Technique International Office of Epizootics 27, pp.161-173.

13. Paez-Osuna F, Gracia A, Flores-Verdugo F, Lyle-Fritch LP, Alonso-Rodraguez R, Roque A, Ruiz-Fernandez AC (2003). Shrimp aquaculture development and the environment in the Gulf of California ecoregion. Mar. Pollut. Bull. 46, pp 806-815.

14. Peng SE, Lo CF, Lin SC, Chen LL, Chang YS, Liu KF, Su MS and Kou GH (2001).

15. Patton MQ (2002). Qualitative Research and Evaluation Methods. Thousand Oaks, CA: Sage.

16. SEAT (2014). Sustainable Ethical Aquaculture Trade [Online] Available at http://seatglobal.eu/. [Accessed on: 15/05/2015].

17. Stentiford G and Lightner D (2011). Cases of white spot disease (WSD) in European shrimp farms. Aquaculture 319: 302-306.

18. Taskov D (2014). Qualitative assessment of the long-term impacts of the CARE GOLDA project on freshwater prawn farming methods and communities in Bagerhat district of Bangladesh. University of Stirling. pp. 1-64.

19. Withyachumnarnkul B (1999). Results from black tiger shrimp Penaeus monodon culture ponds Stocked with postlarvae PCR-positive or -negative for white-spot syndrome virus (WSSV). Diseases of Aquatic Organisms 39: 21-27. 